УДК 616.89-008.441.13-055.2:615.851:316.628

Для цитирования: Пешковская А.Г., Мандель А.И., Белокрылов И.И., Назарова И.А., Кисель Н.И. Проблема анозогнозии при женском алкоголизме: мишени и эффективность терапевтического воздействия. Сибирский вестник психиатрии и наркологии. 2017; 3 (96): 57—63. https://doi.org/10.26617/1810-3111-2017-3(96)-57-63

\title{
Проблема анозогнозии при женском алкоголизме: мишени и эффективность терапевтического воздействия
}

\section{Пешковская А.Г., Мандель А.И., Белокрылов И.И., Назарова И.А., Кисель Н.И.}

Научно-исследовательский институт психического здоровья

Томский национальный исследовательский медицинский центр Российской академии наук

Россия, 634014, Томск, ул. Алеутская, 4

\section{PEЗЮME}

Цель: определение и апробация психодиагностического инструментария, способного путем преодоления алкогольной анозогнозии у женщин выявлять мишени персонализированной психотерапии, динамическая оценка анозогнозии до и после терапии. Материалы. Клинико-динамически и экспериментально-психологически обследовано 30 женщин с ал-

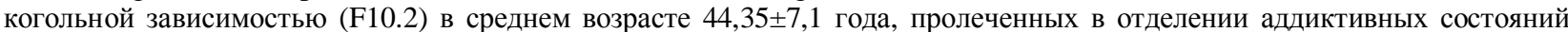
НИИ психического здоровья. Методы. Опросник «Алкогольная анозогнозия», тест смысложизненных ориентаций, шкала тревоги и депрессии HADS. Результаты. В статье представлена апробация комплексного психодиагностического инструментария, способного на основе преодоления алкогольной анозогнозии у женщин решать задачи выявления мишеней персонализированного психотерапевтического воздействия, в том числе осуществлять динамическую оценку анозогнозии - до и после терапии, оценивать её эффективность. Заключение. В исследовании показана целесообразность и эффективность применения определенного психодиагностического инструментария для оценки результатов терапии, успешность которой в случае женского алкоголизма в значительной степени зависит от прицельной терапевтической работы с анозогнозией на когнитивном, эмоциональном и мотивационном уровнях и коррекции ценностно-смысловых аспектов мотивации к лечению.

Ключевые слова: алкогольная зависимость, анозогнозия, женский алкоголизм, мишени персонализированной терапии, оценка эффективности терапии.

Статья подготовлена в рамках выполнения медицинских технологий «Психотерапевтическая когнитивно-поведенческая интервенция для коррекции анозогнозии у наркологических больных», «Технология повышения эффективности персонализированной терапии на основе преодоления анозогнозии у женщин, больных алкоголизмом».

\section{ВВЕДЕНИЕ}

Отрицание у себя заболевания, некритичное отношение к своему заболеванию - анозогнозия - распространенный феномен у больных алкоголизмом. Большинство пациентов с алкогольной зависимостью обращаются за медицинской помощью в развернутой стадии заболевания, при которой доминирует частичная анозогнозия [2, 3, 4, 5, 7, 13, 15]. В клинической картине алкоголизма феномен нарушения сознания болезни и её отрицания присутствует постоянно, что может рассматриваться как облигатный симптомокомплекс $[6,7,21]$. Уровень анозогнозии также определяет прогноз заболевания, являясь предиктором как длительности ремиссий, так и их качества [10, 21, 25, 27].

У женщин алкогольная зависимость характеризуется меньшей курабельностью и несет более серьезную стигматизирующую нагрузку, чем мужской алкоголизм, что способствует длительному сокрытию болезни и её симптомов и формированию устойчивых форм отрицания заболевания и необходимости лечения $[20,21,26]$. Алкогольная анозогнозия у женщин также подкрепляется сильным аффективным компонентом тревожно-дистимического спектра [7, 24, 28]. Специфические особенности депрессивных нарушений, отрицание наличия депрессии, «депрессивная анозогнозия»- всё это требует дополнительных психотерапевтических мишеней [21]. Отрицание болезни, сокрытие наиболее неприятных эпизодов алкогольного прошлого и вытекающее отсюда сопротивление психотерапевтическим воздействиям вызвано осознанным или неосознанным стремлением избежать женщинами «клейма» алкоголизма, которое серьезно подрывает репутацию $[5,12,17]$.

Динамическая оценка анозогнозии является необходимой составляющей терапевтического процесса. Успешность лечебно-реабилитационной перспективы напрямую зависит от того, насколько полно пациенты с алкогольной зависимостью признают свою болезнь и осознают необходимость лечения [29].

Таким образом, преодоление анозогнозии становится одной из основных задач, реализация которой связана с эффективностью изменения всей системы отношений больных, деформированной алкоголизацией, коррекцией ценностных ориентаций и дезадаптивных стереотипов межличностных отношений, прежде всего в семье [27].

Применение когнитивно-поведенческой интервенции, предназначенной для коррекции проявлений анозогнозии, позволит повысить мотивацию к лечению, сформировать новое адаптивное поведение у женщин с алкоголизмом, повысить эффективность лечебных и психотерапевтических мероприятий [15]. 
В свою очередь динамическая оценка анозогнозии при женском алкоголизме выступает необходимой составляющей терапевтического процесса, так как характеристики и выраженность данного симптомокомплекса влияют на особенности психотерапевтических и реабилитационных программ $[1,8,23]$.

Цель исследования - определение и апробация комплексного психодиагностического инструментария, способного на основе преодоления алкогольной анозогнозии у женщин решать задачи выявления мишеней персонализированного психотерапевтического воздействия, в том числе осуществлять динамическую оценку анозогнозии - до и после терапии, оценивать её эффективность.

\section{МАТЕРИАЛЫ И МЕТОДЫ}

Клинико-динамическому и экспериментальнопсихологическому обследованию было подвергнуто 30 женщин, страдающих алкогольной зависимостью (F10.2) и проходивших лечение в отделении аддиктивных состояний НИИ психического здоровья (средний возраст 44,35+7,1 года). Критериями исключения явились состояние абстиненции, сопутствующие психические расстройства психотического регистра (шизофрения, биполярное аффективное расстройство и др.), органическая патология головного мозга, состояния острых или обострения хронических соматических заболеваний.

Для выявления мишеней персонализированной терапии и оценки эффективности терапии был отобран следующий психодиагностический инструментарий: опросник «Алкогольная анозогнозия» [16], тест смысложизненных ориентаций Д.А. Леонтьева, шкала тревоги и депрессии HADS (Hospital Anxiety and Depression Scale, Zigmond A.S., Snaith R.P., 1983).

Основанием для выбора данного комплекса психодиагностических методов явились следующие его преимущества: задействует как когнитивный, так и эмоциональный, мотивационный, ценностный уровни для определения мишеней терапии в рамках одного психодиагностического исследования; предоставляет возможность разработки индивидуальных рекомендаций для каждого больного в отдельности; предоставляет возможность динамической оценки исследуемых параметров в рамках модели «тест-ретест»; экспресс-диагностика [11, 12, 19].

Статистическая обработка данных проводилась с использованием пакета прикладных программ STATISTICA 10.0. Результаты психодиагностики до и после терапии сравнивали с использованием критерия знаков и критерия парных сравнений Вилкоксона.

\section{РЕЗУЛЬТАТЫ И ОБСУЖДЕНИЕ}

Диагностика уровня алкогольной анозогнозии с помощью опросника «Алкогольная анозогнозия», разработанного авторами на основе концепции отношений В.Н. Мясищева (1960) и представлениях A. S. David (1990) и X.F. Amador (1991) о структуре отношения больного к психическому заболеванию, позволила получить комплексную экспресс-оценку уровня алкогольной анозогнозии до и после терапии по отдельным её компонентам: когнитивному, эмоциональному, мотивационному. Результаты оценки уровня анозогнозии у женщин с алкогольной зависимостью до и после персонализированной терапии свидетельствуют о положительной динамике в преодолении анозогнозии пациентами (рис. 1).

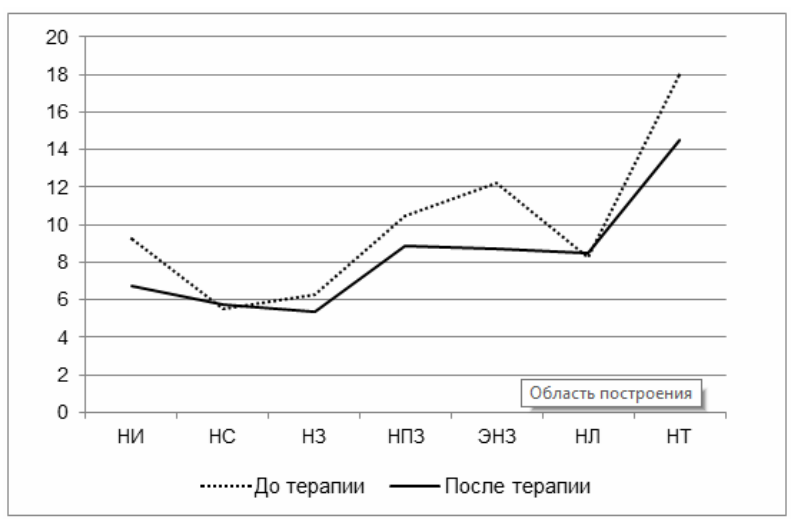

Рисунок 1. Динамика показателей анозогнозии у женщин с алкогольной зависимостью до и после персонализированной терапии

Среднегрупповые показатели по шкале «Неинформированность» (НИ) снизились с 9,25 балла до терапии до 6,7 балла после ( $=0,048)$, что отражает повышение информированности женщин о медицинской модели алкогольной зависимости, причинах возникновения болезни и способах её лечения.

Среднегрупповые показатели по шкале «Непризнание симптомов заболевания» (НС) не изменились в динамике.

Представляется, что терапевтическая работа по преодолению данного когнитивного компонента анозогнозии требует большего числа психотерапевтических сессий в отношении отдельных пациентов. Однако отметим, что уровень анозогнозии 70\% женщин в выборке снижается, так как персонализированная терапия способствует осознанию и принятию факта наличия симптомов алкоголизма: абстинентных расстройств и утраты количественного контроля.

Женщины с алкогольной зависимостью также демонстрируют снижение показателя анозогнозии по шкале «Непризнание заболевания» (Н3). Средние значения в выборке до и после персонализированной терапии составляют соответственно 6,25 и 5,5 балла, что свидетельствует о динамике в отношении принятия факта заболевания.

На средний показатель по шкале «Непризнание последствий заболевания» (НПЗ) оказывают влияние отдельные оценки больных алкоголизмом женщин роли иных обстоятельств, но не фактора алкогольной зависимости в имеющихся в разных сферах жизни проблемах. Однако в целом зафиксировано снижение показателей данного когнитивного компонента анозогнозии с 10,5 балла до 8,9 после терапии, т.е. женщины признают наличие медицинских, 
психологических и социальных проблем, связанных именно с алкоголизацией.

Средние показатели по шкале «Эмоциональное непринятие заболевания» (ЭНЗ) после персонализированной терапии понижаются с 12,25 до 8,68 балла $(\mathrm{p}=0,029)$, что свидетельствует о значительной динамике в эмоциональной сфере - повышении эмоциональной озабоченности женщин по поводу как заболевания в целом, так и в отношении отдельных его аспектов.

Показатели по шкале «Несогласие с лечением» (НЛ) свидетельствуют о пассивном отношении к лечению, не изменяющемся в динамике. Отметим, что данный показатель сопровождается преобладанием более низких оценок по шкале «Локус контроль - Я» в противовес более высоким значениям по шкале «Локус контроль - жизнь» теста СЖО, что связано со снижением у женщин веры в себя, недооценкой способностей контролировать события своей жизни, в том числе в результате осознания сложности пути излечения и установки на передачу функции контроля над собственной жизнью лечащему врачу и значимым близким.

Среднегрупповые показатели по шкале «Непринятие трезвости» (НТ) составили 18 баллов до терапии и 14,5 балла после $(\mathrm{p}=0,041)$, что отражает повышение уровня мотивации женщин с алкогольной зависимостью на трезвый образ жизни, высказывание необходимости трезвости.

Статистические данные когорты пациентов по шкалам опросника «Алкогольная анозогнозия» представлены в таблице 1.

Таблица 1

\begin{tabular}{|c|c|c|c|c|c|}
\hline $\begin{array}{r}\text { Динамика показат } \\
\text { с алкогольной за } \\
\text { и после (Тест 2) пер }\end{array}$ & $\begin{array}{l}\text { елеи аң } \\
\text { висим } \\
\text { сональ }\end{array}$ & & нHOИ & $\begin{array}{l}\text { ст 1) } \\
\text { герап }\end{array}$ & \\
\hline Показатель анозогнозии & $\mathrm{Tec}$ & & & & p-lev \\
\hline & Mean & SD & Mean & SD & \\
\hline Неинформированность & 9,25 & 2,06 & 6,70 & 1,73 & 0,048 \\
\hline $\begin{array}{l}\text { Непризнание симптомов } \\
\text { заболевания }\end{array}$ & 5,50 & 1,91 & 5,73 & 1,83 & 1,003 \\
\hline Непризнание заболевания & 6,25 & 2,63 & 5,35 & 1,73 & 0,437 \\
\hline $\begin{array}{l}\text { Непризнание последствий } \\
\text { заболевания }\end{array}$ & 10,50 & 2,38 & 8,90 & 2,00 & 0,051 \\
\hline $\begin{array}{l}\text { Эмоциональное непринятие } \\
\text { заболевания }\end{array}$ & 12,25 & 2,75 & 8,68 & 1,26 & 0,029 \\
\hline Несогласие с лечением & 8,25 & 0,96 & 8,50 & 1,91 & 0,993 \\
\hline Непринятие трезвости & 18,00 & 3,74 & 14,50 & 5,80 & 0,041 \\
\hline
\end{tabular}

Диагностика ценностно-смысловых компонентов мотивации к лечению больных алкоголизмом у женщин, выполненная с привлечением теста смысложизненных ориентаций Д.А. Леонтьева до и после персонализированной терапии, позволила установить положительную динамику ценностносмысловых аспектов мотивации пациентов.

Показатель целей, характеризующий наличие в жизни пациента целей в будущем, которые придают жизни осмысленность, направленность и временную перспективу, возрос в среднем с 29,75 до 31,78 балла после персонализированной терапии соответственно (рис. 2).
Показатели по шкале «Процесс жизни» теста СЖО отражают наличие интереса и эмоциональной насыщенности жизни. Этот показатель также говорит о том, воспринимает ли женщина сам процесс своей жизни как интересный, эмоционально насыщенный, наполненный смыслом. Высокие баллы по этой шкале и низкие значения по остальным шкалам характеризуют обследованного как гедониста, живущего сегодняшним днем. Низкие баллы по этой шкале рассматриваются как неудовлетворенность своей жизнью в настоящем. В исследуемой выборке женщин с алкогольной зависимостью средние баллы по данной шкале возросли с 22,5 до 25 (рис. 2), что свидетельствует о повышении эмоциональной насыщенности жизни и интереса к ней после персонализированной терапии на основе преодоления анозогнозии, что позволяет использовать данный мотивационный компонент в качестве повышающего мотивацию к лечению.

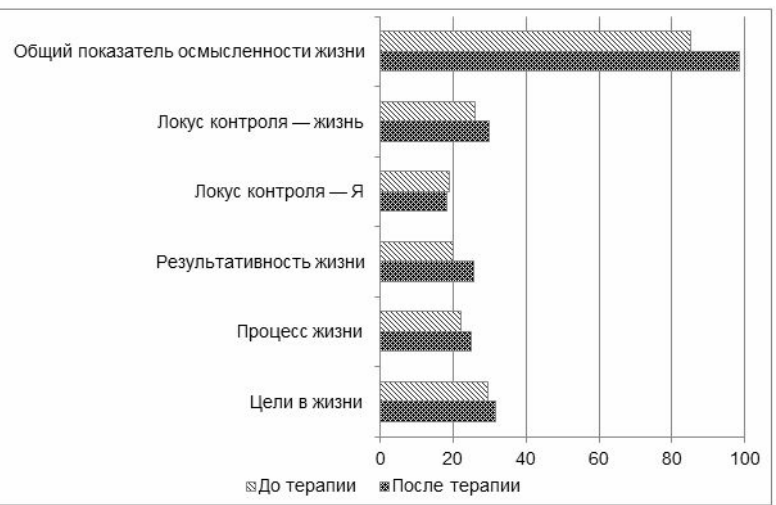

Рисунок 2. Динамика показателей смысложизненных ориентаций женщин с алкогольной зависимостью до и после персонализированной терапии

Баллы по шкале «Результативность жизни» отражают оценку женщинами, больными алкоголизмом, пройденного отрезка жизни, ощущение того, насколько продуктивна и осмыслена была прожитая её часть. Зафиксированный достоверно значимый рост среднегрупповых показателей с 20,25 до 26,75 балла после персонализированной терапии $(\mathrm{p}=0,045)$ свидетельствует о возрастании значимости прошлого, способного придать осмысленность текущему периоду жизни, что также позволяет использовать данный смысловой компонент для преодоления алкогольной анозогнозии и повышения мотивации к лечению.

Значения показателей «Локус контроль - Я», «Локус контроль - жизнь» меняются незначительно, что связано со стабильностью и малой чувствительностью к изменениям данных характеристик как черт личности. В исследуемой когорте женщин в отношении данных показателей наблюдается снижение веры в свои силы, недооценка своих способностей контролировать события жизни, в том числе появившихся как результат осознания сложности пути преодоления алкогольной зависимости и внутренней установки на передачу функции контроля 
над собственной жизнью лечащему врачу и значимым близким.

Вместе с тем положительная динамика после психотерапевтической интервенции наблюдается в отношении общего показателя осмысленности жизни, значения которого возрастают с 85,40 до 98,75 балла (p=0,037). Положительная динамика подтверждает эффективность психотерапевтических мероприятий для повышения общей осмысленности жизни, осознания собственной личности и роли болезни и излечения в жизненном пути пациентов.

Статистические данные когорты пациентов по показателям теста СЖО представлены в таблице 2.

Т а б л и ц а 2 Динамика показателей смысложизненных ориентаций до (Тест 1) и после (Тест 2) персонализированной терапии

\begin{tabular}{|l|c|c|c|c|c|}
\hline \multicolumn{1}{|c|}{ Показатель } & \multicolumn{2}{|c|}{ Тест 1 } & \multicolumn{2}{c|}{ Тест 2 } & p-level \\
\cline { 2 - 6 } & Mean & SD & Mean & SD & \\
\hline Цели в жизни & 29,75 & 8,26 & 31,78 & 8,49 & 0,729 \\
\hline Процесс жизни & 22,50 & 6,03 & 25,00 & 4,55 & 0,075 \\
\hline Результативность жизни & 20,25 & 4,57 & 26,75 & 5,62 & 0,045 \\
\hline Локус контроля - Я & 19,00 & 6,16 & 18,55 & 6,65 & 0,976 \\
\hline Локус контроля - жизнь & 26,25 & 4,99 & 30,00 & 9,02 & 0,730 \\
\hline $\begin{array}{l}\text { Общий показатель } \\
\text { осмысленности жизни }\end{array}$ & 85,40 & 16,68 & 98,75 & 18,01 & 0,037 \\
\hline
\end{tabular}

Оценка депрессии и тревоги у женщин с алкогольной зависимостью по шкале тревоги и депрессии HADS (Hospital Anxiety and Depression Scale) позволила диагностировать снижение индекса тревоги с 12,0 до 7,2 балла в среднем (рис. 3 ).

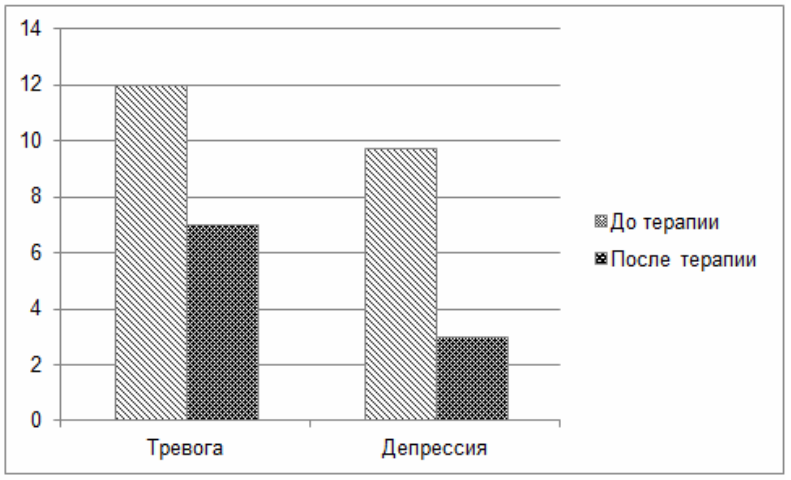

Рисунок 3. Динамика показателей тревоги и депрессии по шкале HADS до и после персонализированной терапии

Индекс депрессии до и после персонализированной терапии составил соответственно 9,75 и 3,0 балла, что свидетельствует о значительной динамике данного показателя в сторону улучшения психического состояния женщин $(\mathrm{p}=0,042)$ и подтверждает эффективность терапевтических мероприятий. Статистические данные когорты пациентов по показателям шкалы HADS представлены в таблице 3.

Т а б л и ц а 3

Динамика показателей тревоги и депрессии

\begin{tabular}{l|c|c|c|c|c|} 
до (Тест 1) и после (Тест 2) персонализированной терапии \\
\hline \multirow{2}{*}{ Показатель } & \multicolumn{2}{|c|}{ Тест 1 } & \multicolumn{2}{|c|}{ Тест 2 } & \multirow{2}{*}{ p-level } \\
\cline { 2 - 5 } & Mean & SD & Mean & SD & \\
\hline Тревога & 12,00 & 3,56 & 7,20 & 1,41 & 0,133 \\
\hline Депрессия & 9,75 & 7,04 & 3,00 & 1,83 & 0,042 \\
\hline
\end{tabular}

По результатам персонализированной терапии зафиксирована положительная динамика в преодолении анозогнозии, в частности её когнитивного, эмоционального и мотивационного компонентов. Среднегрупповые показатели по шкале «Неинформированность» имели достоверную тенденцию к снижению с 9,25 до 6,7 балла после терапии ( $\mathrm{p}=0,048)$, что свидетельствует о повышении уровня информированности женщин о медицинской модели алкогольной зависимости, причинах возникновения болезни и способах её лечения. Снижение показателя по шкале «Непризнание заболевания» с 6,25 до 5,5 балла после персонализированной терапии связано с принятием факта заболевания. Женщины также признают наличие медицинских, психологических и социальных проблем, связанных с алкоголизацией, данное положение подтверждается снижением значений показателя «Непризнание последствий заболевания» с 10,5 балла до 8,9 после терапии.

Показатели по шкале «Эмоциональное непринятие заболевания» после персонализированной терапии достоверно снижаются с 12,25 до 8,68 балла $(\mathrm{p}=0,029)$, что свидетельствует о значительной динамике в эмоциональной сфере - повышении эмоциональной озабоченности женщин по поводу своего заболевания и его отдельных аспектов. Снижение показателей по шкале «Непринятие трезвости» с 18 до 14,5 балла отражает повышение на достоверном уровне мотивации на трезвый образ жизни $(\mathrm{p}=0,041)$.

Установлена положительная динамика ценностно-смысловых аспектов мотивации на лечение: отмечается достоверно значимый рост среднегрупповых показателей субъективной результативности $(\mathrm{p}=0,045)$ и осмысленности жизни $(\mathrm{p}=0,037)$, что в свою очередь доказывает эффективность психотерапевтических мероприятий для повышения общей осмысленности жизни, осознания собственной личности, признания наличия болезни и её роли в жизненном пути пациентов.

Уставлено снижение тревоги и депрессивных тенденций, наличие которых до терапии выступало в роли блокирующих процессов осознания болезни. Выраженность депрессии до и после персонализированной терапии составила соответственно 9,75 и 3,0 балла, что свидетельствует о достоверно значимой положительной динамике данного показателя в сторону улучшения психического состояния женщин с алкогольной зависимостью $(\mathrm{p}=0,042)$.

\section{ЗАКЛЮЧЕНИЕ}

Таким образом, в исследовании показана целесообразность и эффективность применения предложенного комплексного психодиагностического инструментария в отношении следующих задач терапии женского алкоголизма: выявление мишеней психотерапевтического воздействия на этапе до терапии, в том числе динамическая оценка анозогнозии, а также оценка результатов персонализирован- 
ной терапии, успешность которой в случае женского алкоголизма в значительной степени зависит от прицельной терапевтической работы с анозогнозией на когнитивном, эмоциональном и мотивационном уровнях и коррекции ценностно-смысловых аспектов мотивации к лечению. Кроме того, комплексный психодиагностический инструментарий эффективен для разработки индивидуальных рекомендаций для каждого больного с целью повышения его реабилитационного потенциала.

Разработка компетентных критериев диагностики и оценки программ терапии является приоритетным и социально значимым направлением современной наркологии. Комплексный метод выявления мишеней и оценки эффективности терапии на основе преодоления анозогнозии у женщин с алкогольной зависимостью выступает необходимым компонентом лечебно-реабилитационных мероприятий, позволяет оценить результат психотерапевтического воздействия и прогнозировать устойчивость ремиссии.

\section{КОНФЛИКТ ИНТЕРЕСОВ}

Авторы заявляют об отсутствии конфликта интересов в связи с публикацией данной статьи.

\section{ИСТОЧНИК ФИНАНСИРОВАНИЯ}

Исследование проведено по теме, выполняемой в рамках поисковых научных исследований НИИ психического здоровья «Разработка методов персонализированной терапии у больных аддиктивными расстройствами». Шифр темы 0550-2016-0401. Номер госрегистрации АААА-А16-116042610053-7.

\section{СООТВЕТСТВИЕ ПРИНЦИПАМ ЭТИКИ}

Работа соответствует этическим стандартам, разработанным в соответствии с Хельсинской декларацией ВМА (протокол заседания этического комитета при НИИ психического здоровья Томского НИМЦ № 85 от 14.12. 2015 г., дело № 85/5.2015).

\section{ЛИТЕРАТУРА}

1. Агибалова Т. В., Бузик О. Ж. Психотерапия в наркологии. Российский медико-биологический вестник им. акад. И.П. Павлова. 2007; 2. URL: http://cyberleninka.ru/article/n/psihoterapiya-vnarkologii (дата обращения: 25.03.2017).

2. Баранова О.В. Алкогольная анозогнозия и её преодоление в процессе лечения больных алкоголизмом: автореф. дис. ... к.м.Н.. М., 2005: 26.

3. Бохан Н.А., Семке В.Я. Коморбидность в наркологии. Томск : Изд-во Том. ун-та, 2009: 510.

4. Бохан Н. А., Мандель А. И., Кузнецов В. Н. Алкогольная смертность в отдалённых сельских районах Западной Сибири. Наркология. 2011; 10, 9 (117): 43-47.

5. Бохан Н.А., Мандель А.И., Пешковская А.Г., Бадыргы И.О., Асланбекова Н.В. Этнотерриторальная гетерогенность формирования алкогольной зависимости у коренного населения Сибири. Журнал неврологии и психиатрии им: С.С. Корсакова. 2013; 6: 9-14.

6. Габоев В.Н. Алкогольная анозогнозия - ведущий психопатологический синдром хронического алкоголизма. Медицинские науки. 2010; 3: 19-23.

7. Демина М.В. О механизмах нарушения сознания наркологической болезни и подходах к его коррекции. Вопросы наркологии. 2005; 1: 13-21.

8. Игонин А.Л. Психотерапевтические методы лечения наркологических заболеваний. Наркологические заболевания в лечебной и экспертной практике. М.: ФГУ «ГНЦ ССП Росздрава», 2008: 247-256.
9. Карвасарский Б.Д. Анозогнозия наркологических больных / Психотерапевтическая энциклопедия / под ред. Б.Д. Карвасарского. СПб.: Питер, 2000: 345.

10. Киржанова В.В., Григорова Н.И., Сидорюк О.В. Основные показатели деятельности наркологической службы в Российской Федерации в 2013-2014 годах: статистический сборник. М., 2016: 141.

11. Пешковская А.Г. Этнокультуральный диспаритет когнитивных нарушений при алкоголизме. Неврологический вестник им. В.М. Бехтерева. 2014; XLVI (3): 97-98.

12. Пешковская А.Г., Мандель А.И., Бадыргы И.О. Этнический фактор и проблема алкоголизма (обзор литературы). Becmник Томского государственного педагогического универсиmema. 2015; 3 (156): 49-57.

13. Пешковская А.Г., Мандель А.И., Бадыргы И.О., Бохан Н.А., Иванова С.А., Федоренко О.Ю. Психологические особенности больных алкоголизмом различных этнических групп коренного населения Сибири. - Томск: «Иван Федоров», 2015. $-45 \mathrm{c}$.

14. Пешковская А.Г., Мандель А.И., Белокрылов И.И., Назарова И.А. Психотерапевтическая когнитивно-поведенческая интервенция для коррекции анозогнозии у наркологических больных. Томск: «Иван Федоров», 2016: 21.

15. Пешковская А.Г., Мандель А.И., Белокрылов И.И., Назарова И.А., Кисель Н.И. Технология повышения эффективности персонализированной терапии на основе преодоления анозогнозии у женщин, больных алкоголизмом. Томск: «Иван Федоров», 2017: 24

16. Поляк О.Б. Критика к заболеванию и терапевтическая мотивация в структуре отношения к болезни при опиоидных наркоманиях: автореф. дис. ... к.п.н. СПб., 2009: 23.

17. Рыбакова Ю.В., Илюк Р.Д., Крупицкий Е.М., Бочаров В.В., Вукс А.Я. Методика оценки анозогнозии у больных алкоголизмом: методические рекомендации. СПб., 2011: 37.

18. Семке В.Я., Мельникова Т.Н., Бохан Н.А. Нейробиологические механизмы алкоголизма. Журнал неврологии и психиатрии им. С.С. Корсакова. 2002; 102 (8): 61-66.

19. Сомкина О.Ю., Меринов А.В., Байкова М.А. Отличительные особенности наркологической характеристики женщин и мужчин, страдающих алкогольной зависимостью, в контексте аутоагрессивного поведения. Российский медико-биологический вестник им. акад. И.П. Павлова. 2016; 4. URL: http://cyberleninka.ru/article/n/otlichitelnye-osobennosti-narkologicheskoy-harakteristiki-zhenschin-i-muzhchin-stradayuschih-alkogolnoy-zavisimostyu-v-kontekste (дата обращения: 06.04.2017).

20. Хоютанова Н.В., Матвеева Н.П., Бохан Н.А., Иванова С.А., Кривошапкина 3.Н., Иготти Е.А. Клинико-динамические особенности формирования и течения алкоголизма у женщин в зависимости от климатогеографических условий проживания на территории РС (Я). Якутский медищинский журнал. 2015; 1 (49): 14-18.

21. Шайдукова Л.К. Конституционально-психологические особенности нарушений полоролевого поведения женщин, злоупотребляющих алкоголем. ПМ. 2012; 57. URL: http://cyberleninka.ru/article/n/konstitutsionalno-psihologicheskieosobennosti-narusheniy-polorolevogo-povedeniya-zhenschinzloupotreblyayuschih-alkogolem (дата обращения: 06.04.2017).

22. Bokhan N. A., Ovchinnikov A. A. Dissociative model of addictions formation. Saint-Louis, MO, USA: Publishing House Science and Innovation Center, 2014: 324.

23. Bokhan N.A., Mandel A.I., Stoyanova I.Ya., Mazurova L.V., Aslanbekova N.V. Psychological Defense and Strategies of Coping in Alcohol Dependence and Co-Dependence in Women. J. Psychol. Psychother. 2013; 3: 128. doi: 10.4172/2161-0487.1000128

24. Esper L.H., Furtado E.F. Gender differences and association between psychological stress and alcohol consumption: A systematic review. Alcoholism \& Drug Dependance. 2013; 1: 116-120.

25. Laudet A., Stanick V. Predictors of motivation for abstinence at the end of outpatient substance abuse treatment. Journal of Substance Abuse Treatment. 2010; 38: 317-327.

26. Lewis B., Nixon S.J. Characterizing Gender Differences in Treatment Seekers. Alcohol Clin. Exp. 2014; 38 (1):275-84. doi: 10.1111/acer.12228. 
27. Litt M. D., Kadden R. M., Tennen H. Network Support treatment for alcohol dependence: gender differences in treatment mechanisms and outcomes. Addictive behaviors. 2015; 45: 87-92.

28. Petit G., Luminet O., de Sousa Uva M. et al. Gender differences in affects and craving in alcohol-dependence: A study during alcohol detoxification. Alcoholism: Clinical and Experimental Research. 2017; 41, 421-431. doi:10.1111/acer.13292.
29. Ruiz S.M., Oscar-Berman M. Closing the Gender Gap: The Case for Gender-Specific Alcoholism Research. Alcoholism \& Drug Dependance. 2013: 1: e106. doi:10.4172/2329-6488.1000e106.

Поступила в редакцию 20.04.2017 Утверждена к печати 26.06.2017

Пешковская Анастасия Григорьевна, м.н.с. отделения аддиктивных состояний.

Мандель Анна Исаевна, д.м.н., проф., в.н.с. отделения аддиктивных состояний.

Белокрылов Илья Игоревич, м.н.с. отделения аддиктивных состояний.

Назарова Ирина Анатольевна, м.н.с. отделения аддиктивных состояний.

Кисель Наталья Игоревна, к.м.н., врач отделения аддиктивных состояний.

Мандель Анна Исаевна, anna-mandel@mail.ru

УДК 616.89-008.441.13-055.2:615.851:316.628

For citation: Peshkovskaya A.G., Mandel A.I., Belokrylov I.I., Nazarova I.A., Kisel N.I. Problem of anosognosia in female alcoholism: targets and efficiency of therapeutic intervention. Siberian Herald of Psychiatry and Addiction Psychiatry. 2017; 3 (96): 57-63. https://doi.org/10.26617/1810-3111-2017-3(96)-57-63

\section{Problem of anosognosia in female alcoholism: targets and efficiency of therapeutic intervention}

\section{Peshkovskaya A.G., Mandel A.I., Belokrylov I.I., Nazarova I.A., Kisel N. I.}

\section{Mental Health Research Institute, Tomsk National Research Medical Center, Russian Academy of Sciences} Aleutskaya Street 4, 634014, Tomsk, Russian Federation

\section{ABSTRACT}

Objective: to identify and test psychodiagnostic tools capable by the way of overcoming the alcohol anosognosia in women to reveal targets of personalized psychotherapy, to evaluate in dynamics the anosognosia at baseline and after therapy. Materials. Clinical-dynamic and experimental-psychological examination of 30 women with alcohol dependence (F10.2) aged 44.35 \pm 7.1 years under therapy at Addictive States Department of Mental Health Research Institute was carried out. Methods. Questionnaire "Alcohol Anosognosia", Test of Life-Purpose Orientations, Hamilton Anxiety and Depression Scale (HADS). Results. This paper presents approbation of complex psychodiagnostic tools capable by the way of overcoming the alcohol anosognosia in women to solve tasks of revealing the "targets" of personalized psychotherapeutic intervention and to evaluate the anosognosia in dynamics at baseline and after therapy, to evaluate its efficiency. Conclusion. The study showed appropriateness and efficiency of the use of some psychodiagnostic tools for evaluation of results of the therapy, which success in female alcoholism to significant degree depends on targeted therapeutic work with anosognosia at cognitive, emotional and motivational levels and correction of valuemeaning aspects of motivation to treatment.

\section{Keywords: alcohol dependence, anosognosia, female alcoholism, personalized therapy targets, therapy efficiency evaluation.}

\section{REFERENCES}

1. Agibalova T.V., Buzik O.Zh. Psikhoterapiya v narkologii [Psychotherapy in narcology]. Ros. mediko-biol. vestn. im. akad. I.P. Pavlova - I.P. Pavlov Russian Medical-Biological Bulletin. 2007; 2. URL: http://cyberleninka.ru/article/n/psihoterapiya-vnarkologii (date of address: 25.03.2017) (in Russian).

2. Baranova O.V. Alkogol'naya anozognoziya i ee preodolenie v protsesse lecheniya bol'nykh alkogolizmom [Alcohol anosognosia and its overcoming in the process of therapy of alcoholic patients]. Avtoref. dis. ... k.m.n. - Abstract of PhD thesis. M., 2005: 26 (in Russian).

3. Bokhan N.A., Semke V.Ya. [Co-morbidity in Addiction Psychiatry]. Tomsk: Publishing House of Tomsk University, 2009. 510 p. (in Russian).

4. Bokhan N.A., Mandel A.I., Kuznetsov V.N. [Alcohol mortality in remote rural districts of West Siberia]. Narkologiya [Narcology]. 2011; 10, 9 (117): 43-47. (in Russian).

5. Bokhan N.A., Mandel A.I., Peshkovskaya A.G., Badyrgy I.O., Aslanbekova N.V. Etnoterritoral'naya geterogennost' formirovaniya alkogol'noy zavisimosti u korennogo naseleniya Sibiri [Ethnoterritorial heterogeneity of alcohol dependence formation in the native population of Siberia]. Zhurnal nevrologii i psikhiatrii im: S.S. Korsakova - S.S. Korsakov Journal of Neurology and Psychiatry. 2013; 6: 9-14 (in Russian).

6. Gaboev V.N. Alkogol'naya anozognoziya - vedushchiy psikhopatologicheskiy sindrom khronicheskogo alkogolizma
[Alcohol anosognosia - a leading psychopathological syndrome of chronic alcoholism]. Meditsinskie nauki - Medical Sciences. 2010; 3: 19-23 (in Russian).

7. Demina M.V. O mekhanizmakh narusheniya soznaniya narkologicheskoy bolezni i podkhodakh k ego korrektsii [About mechanisms of disturbance of perception of a narcological illness and approaches to its correction]. Voprosy narkologii Journal of Addiction Problems. 2005; 1: 13-21 (in Russian).

8. Igonin A.L. Psikhoterapevticheskie metody lecheniya narkologicheskikh zabolevaniy. Narkologicheskie zabolevaniya $\mathrm{v}$ lechebnoy i ekspertnoy praktike [Psychotherapeutic methods of the therapy of narcological disseases. Narcological diseases in therapeutic and expert practice]. M.: FGU "GNTs SSP Roszdrava", 2008: 247-256 (in Russian).

9. Karvasarsky B.D. Anozognoziya narkologicheskikh bol'nykh / Psikhoterapevticheskaya entsiklopediya [Anosognosia of narcological patients]. In: [Psychotherapeutic encyclopedia]. B.D. Karvasarsky, ed. SPb.: Piter, 2000: 345 (in Russian)

10. Kirzhanova V.V., Grigorova N.I., Sidoryuk O.V. Osnovnye pokazateli deyatel'nosti narkologicheskoy sluzhby v Rossiyskoy Federatsii v 2013-2014 godakh: statisticheskiy sbornik [The main indices of activities of narcological service in the Russian Federation in 2013-2014: statistical compendium. M., 2016: 141 (in Russian).

11. Peshkovskaya A.G. Etnokul'tural'nyy disparitet kognitivnykh narusheniy pri alkogolizme [Ethno-cultural disparity of cogni- 
tive disorders in alcoholism]. Nevrologicheskiy vestnik im V.M. Bekhtereva - V.M. Bekhterev Neurological Bulletin. 2014; XLVI (3): 97-98 (in Russian).

12. Peshkovskaya A.G., Mandel A.I., Badyrgy I.O. Etnicheskiy faktor i problema alkogolizma (obzor literatury) [Ethnic factor and problem of alcoholism (literature review)]. Vestnik Tomskogo gosudarstvennogo pedagogicheskogo universiteta Tomsk State Pedagogical University Bulletin. 2015; 3 (156): 4957 (in Russian).

13. Peshkovskaya A.G., Mandel A.I., Badyrgy I.O., Bokhan N.A., Ivanova S.A., Fedorenko O.Yu. Psikhologicheskie osobennost bol'nykh alkogolizmom razlichnykh etnicheskikh grupp korennogo naseleniya Sibiri [Psychological traits of alcoholic pateints from different ethnic groups of the indigenous population of Siberia] Tomsk: "Ivan Fedorov", 2015. 45. (in Russian).

14. Peshkovskaya A.G., Mandel A.I., Belokrylov I.I., Nazarova I.A Psikhoterapevticheskaya kognitivno-povedencheskaya interventsiya dlya korrektsii anozognozii u narkologicheskikh bol'nykh [Psychotherapeutic cognitive-behavioral intervention for correction of anosognosia in narcological patients]. Tomsk: "Ivan Fedorov", 2016: 21 (in Russian).

15. Peshkovskaya A.G., Mandel A.I., Belokrylov I.I., Nazarova I.A., Kisel N.I. Tekhnologiya povysheniya effektivnosti personalizirovannoy terapii na osnove preodoleniya anozognozii u zhenshchin, bol'nykh alkogolizmom [Technology of heightening the efficiency of personalized therapy by the way of overcoming of anosognosia in female alcoholic patients]. Tomsk: "Ivan Fedorov", 2017: 24 (in Russian).

16. Polyak O.B. Kritika k zabolevaniyu i terapevticheskaya motivatsiya $\mathrm{v}$ strukture otnosheniya $\mathrm{k}$ bolezni pri opioidnykh narkomaniyakh [Insight towards the disease and therapeutic motivation in structure of the attitude towards the illness in opioid addictions]. Avtoref. dis. ... k.p.n. - Abstract of PhD thesis in Psychology. SPb., 2009: 23 (in Russian).

17. Rybakova Yu.V., Ilyuk R.D., Krupitsky E.M., Bocharov V.V., Vuks A.Ya. Metodika otsenki anozognozii u bol'nykh alkogolizmom: metodicheskie rekomendatsii [Technique of evaluation of anosognosia in alcoholic patients: Guidelines]. SPb., 2011: 37 (in Russian).

18. Semke V.Ya., Melnikova T.N., Bokhan N.A. [Neurobiologica mechanisms of alcoholism]. Zhurnal nevrologii i psikhiatrii im. S. S. Korsakova [S.S. Korsakov Journal of Neurology and Psychiatry]. 2002; 102, 8: 61-66 (in Russian)

19. Somkina O.Yu., Merinov A.V., Baikova M.A. Otlichitel'nye osobennosti narkologicheskoy kharakteristiki zhenshchin i muzhchin, stradayushchikh alkogol'noy zavisimost'yu, v kontekste autoagressivnogo povedeniya [Distinctive features of narocological characteristics of women and men suffering from alcohol dependence in the context of autoaggressive behavior]. Ros. mediko-biol. vestn. im. akad. I.P. Pavlova - I.P. Pavlov Russian Medical-Biological Bulletin. 2016; 4. URL: http://cyberleninka.ru/article/n/otlichitelnye- osobennosti-narkologi-cheskoy-harakteristiki-zhenschin-i-muzhchinstradayuschih-alkogol-noy-zavisimostyu-v-kontekste (date of address: 06.04.2017) (in Russian).

20. Khoyutanova N.V., Matveeva N.P., Bokhan N.A., Ivanova S.A., Krivoshapkina Z.N., Igotti E.A. Kliniko-dinamicheskie osobennosti formirovaniya i techeniya alkogolizma u zhenshchin $\mathrm{v}$ zavisimosti ot klimatogeograficheskikh usloviy prozhivaniya na territorii RS (Ya) [Clinical-dynamic characteristic of formation and course of alcoholism at women depending on climatic-geographic living conditions in the territory of the Republic of Sakha (Yakutia)]. Yakutskiy meditsinskiy zhurnal - Yakut Medical Journal. 2015; 1 (49): 14-18 (in Russian).

21. Shaidukova L.K. Konstitutsional'no-psikhologicheskie osobennosti narusheniy polorolevogo povedeniya zhenshchin, zloupotreblyayushchikh alkogolem [Constitutional-psychological features of disturbances of sex-role behavior of women with alcohol abuse]. Prakticheskaya meditsina - Practical Medicine. 2012; 57. URL: http://cyberleninka.ru/article/n/konstitutsionalnopsihologicheskie-osobennosti-narusheniy-polorolevogo-povedeniyazhenschin-zloupotreblyayuschih-alkogolem (date of address: 06.04.2017) (in Russian).

22. Bokhan N. A., Ovchinnikov A. A. Dissociative model of addictions formation. Saint-Louis, MO, USA: Publishing House Science and Innovation Center, 2014: 324

23. Bokhan N.A., Mandel A.I., Stoyanova I.Ya., Mazurova L.V. Aslanbekova N.V. Psychological Defense and Strategies of Coping in Alcohol Dependence and Co-Dependence in Women. J. Psychol. Psychother. 2013; 3: 128. doi: 10.4172/2161-0487.1000128

24. Esper L.H., Furtado E.F. Gender differences and association between psychological stress and alcohol consumption: A systematic review. Alcoholism \& Drug Dependence. 2013; 1: 116-120.

25. Laudet A., Stanick V. Predictors of motivation for abstinence at the end of outpatient substance abuse treatment. Journal of Substance Abuse Treatment. 2010; 38: 317-327.

26. Lewis B., Nixon S.J. Characterizing Gender Differences in Treatment Seekers. Alcohol Clin. Exp. 2014; 38 (1):275-84. doi: 10.1111/acer.12228.

27. Litt M. D., Kadden R. M., Tennen H. Network Support treatment for alcohol dependence: gender differences in treatment mechanisms and outcomes. Addictive behaviors. 2015; 45: 87-92.

28. Petit G., Luminet O., de Sousa Uva M. et al. Gender differences in affects and craving in alcohol-dependence: A study during alcohol detoxification. Alcoholism: Clinical and Experimental Research. 2017; 41, 421-431. doi:10.1111/acer.13292.

29. Ruiz S.M., Oscar-Berman M. Closing the Gender Gap: The Case for Gender-Specific Alcoholism Research. Alcoholism \& Drug Dependence. 2013: 1: e106. doi:10.4172/2329-6488.1000e106.

Received April 20.2017 Accepted June 26.2017

Peshkovskaya Anastasia G., junior researcher of Addictive States Department, Mental Health Research Institute, Tomsk National Research Medical Center, Russian Academy of Sciences, Tomsk, Russian Federation.

Mandel Anna I., MD, Prof., leading researcher of Addictive States Department, Mental Health Research Institute, Tomsk National Research Medical Center, Russian Academy of Sciences, Tomsk, Russian Federation.

Belokrylov Ilia I., junior researcher of Addictive States Department, Mental Health Research Institute, Tomsk National Research Medical Center, Russian Academy of Sciences, Tomsk, Russian Federation.

Nazarova Irina A., junior researcher of Addictive States Department, Mental Health Research Institute, Tomsk National Research Medical Center, Russian Academy of Sciences, Tomsk, Russian Federation.

Kisel' Natalia I., PhD, physician of Addictive States Department, Mental Health Research Institute, Tomsk National Research Medical Center, Russian Academy of Sciences, Tomsk, Russian Federation.

Mandel Anna I., anna-mandel@ mail.ru 